\title{
A Morphologic and Morphometric Study of the greater palatine foramen: An osteological study in Upper Egypt
}

\author{
By \\ Mohammed, A.Desouky (a), Salwa, M. Ouies(b) and Abeer,F. Abd \\ EL Naeem(c).
}

(a) Professor of anatomy \& Embryology. Faculty of Medicine. Al-MiniaUniversity.

(b) Lecturer of anatomy\& Embryology. Faculty of Medicine .SohagUniversity. (c)Assistant lecturer.Anatomy \& Embryology department. Sohag University.

\section{Abstract:}

Background:Evidence supports a clear racial variation in the position of the greater palatine foramen. Therefore detailed knowledge of the population specific data on biometric features of the greater palatine foramen will facilitate therapeutic, local anesthetic and surgical manipulations in the maxillo-facial region.

Aims \&Objective: The goal of this study was to elucidate the morphological features and precise anatomical position of the greater palatine foramen in relation to the molar tooth .

Materials andMethods:A total of one hundred adult dry skulls were assessed to determine the position, shape, and straight distance from it to incisive foramen. The position of the greater palatine foramen was determined in relation to the maxillary molars.

Result: The results indicated that $47 \%$ opposite 3rd molar.27\%opposite 2nd molar.26\% between $2^{\text {nd }}$ and 3rd molars. Distance from incisive foramen: on the right side it varied between 30.01 to $40.94 \mathrm{~mm}$. On the left side it varied between 32.1 to $41.4 \mathrm{~mm}$.

Conclusion:The GPF is most frequently palatal to the third maxillary molar. For an edentulous patientthe distance from incisive foramenwas about $30 \mathrm{~mm}$.

Keywords:greater palatine foramen,3rd molar,incisive foramen.

\section{Introduction:}

The hard palate is formed by the union of palatine processes of themaxilla anteriorly and the horizontal plates of the palatine boneposteriorly (Chrcanovic and Custódio, 2010; Ilayperuma et al., 2014). The foramen located postero-laterally, on either side of the bony palatemarks the greater palatine foramen (GPF). It represents the lower end ofthe greater palatine canal which transmits the greater palatine vessels andnerve from the pterygopalatine fossa (Williams et al., 2000 and Teixeiraet al., 2010).

The anterior (greater) palatine nerve supplies the main sensoryinnervation to the palate. It is a branche of the maxillary nerve and passesthrough the greater palatine canal (GPC) to surface on the hard palatefrom the greater palatine foramen (GPF), and continues anteriorly, endingjust short of the front incisors (Sharma \&Garud, 2013).

It supplies mucosa of hard palate, medial wall of maxillary sinus andposterior aspect of lateral wall of nose. Identification of GPF is of primevalue for dentists and the oral and maxillofacial surgeons (Viveka andKumar, 2016).

A large body of evidence shows a clear racial variation in themorphometry and relative position of the greater palatine foramen inrelation to the maxillary molars among different populations (Jaffar andHamadah, 2003; Methathrathip et al., 2005; Saralaya and Nayak,2007; Chrcanovic and 
Custódio, 2010). It is also interesting to note thattraits such as localization of the foramina not only differ betweenpopulations of different geographic zones but also within the inhabitantsof the same geographic environment (Saralaya and Nayak, 2007; Ilayperuma et al., 2009;).

Numerous methods have been employed to produce profound regionalanesthesia of the maxillary arch (Ilayperuma et al., 2014), the mostcommonly described route of administration is inserting a needle into thegreater palatine canal through the greater palatine foramen and depositingthe local anesthetic solution into the superior aspect of thepterygopalatine fossa, where the trunk of the maxillary nerve lies(Baddour, 1979 \&Piagkou et al., 2012).

The maxillary nerve block is an effective method of achieving profoundanesthesia of the hemimaxilla in maxillofacial surgery (Ashwini andJaishree, 2014). It is useful in procedures involving quadrant dentistry orin extensive maxillary surgical procedures (Chopra et al., 2016) to allowexodontia, palatal surgery, quadrant restorative dentistry, Caldwell-Lucprocedure or periodontal therapy (Lepere, 1993).

Whatis more, accurate GPF localization is needed when aiming to mobilize thegreater palatine artery during oroantral fistulae closure usingmucoperiostealpedicled palatal flaps (Bell, 2011 and Piagkou et al.,2012) or during palatal mucosa graft or during palatal mucosa graft harvesting for periodontal proposes(Klosek and Rungruang, 2009).

\section{Materials and Methods:}

The present study was conducted on 100 adult dry skulls obtained from the Department of Human Anatomyon 100 dry, adult human skulls irrespective of sex, randomly selected obtained from Anatomy department of medical College of Qena ,Sohag, Assiut and ElMenya university. The observations were measured on both Right \& Left sides in each skull measured. Unequivocal and well defined points were selected forevaluation. The following measurements and observationswere made: (a) location of the foramen in relation tomaxillary molar teeth(Chopraet al., 2016)., (b)distance from the anterior wall of the GPF to the posteriorborder of the incisive foramen(Chrcanovicand Custódio,

2010)(Figure.1)and(c)measurement

ofantero-posterior and transverse diameter of the foramen (Kumar et al., 2015). The average, largest, and smallest sizes of the different foramina were listed.All these data were measured using a digital verniercalliper with anaccurate resolution up to $0.01 \mathrm{~mm}$ ( Sethi et al., 2014).

\section{Morphometric and Statistical} analysis:

The metric data was analysed statistically with SPSS version 16 (Sethi etal., 2014).Statistical evaluations were performed for each measurement:

- The mean, \pm standard deviation of mean.

- The student comparisons t-test, and value were performed to determine if there was a significant difference between the rightand left sides (Sangari et al., 2015).

Finally the significance was considered according to the level ofsignificance $\mathrm{p}$ value as follows: $\mathrm{P} \geq 0.05$ non significance.

$\mathrm{P}^{*} \leq 0.05$ significant.

$\mathrm{P} * * \leq 0.01$ highly significant.

$\mathrm{P}^{* * *} \leq 0.0001$ very high significant. 


\section{RESULTS}

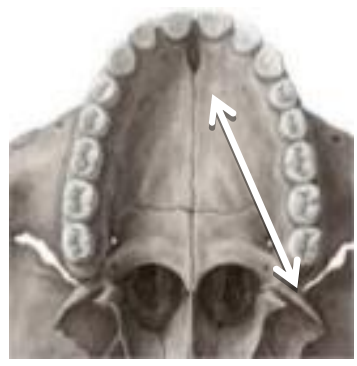

Fig 1.base of skull. arrow between greater palatine foramen and incisive foramen A) Site: $47 \%$ opposite $3 \mathrm{rd}$ molar. $27 \%$ opposite 2 nd molar. $26 \%$ between $2^{\text {nd }}$ and $3 \mathrm{rd}$ molars (figure2).

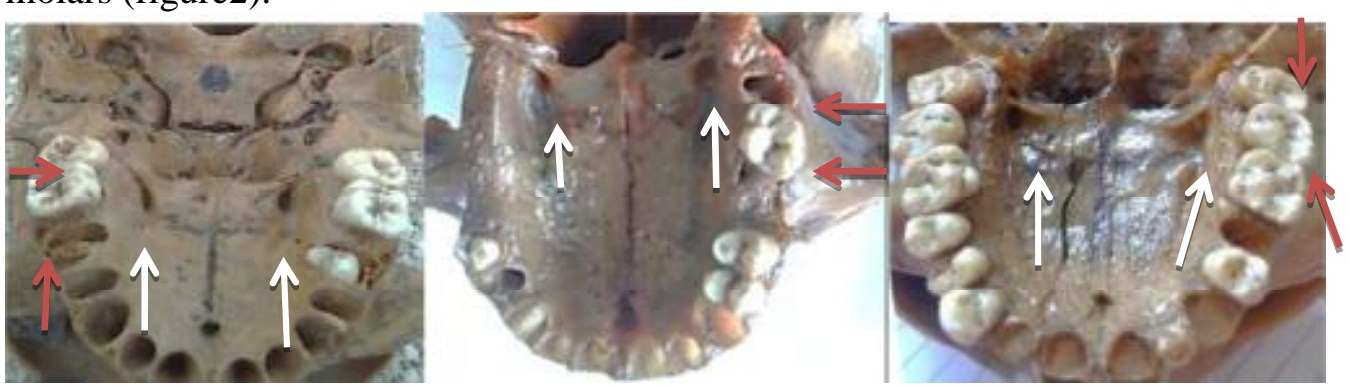

Figure (2): Site of greater palatine foramen (white arrow) (A): Opposite 2nd molar

(B)opposite 3rdmolar (C)between 2nd and 3rd molars(red arrows).

B) Distance from incisive foramen: on the right side it varied between 30.01to $40.94 \mathrm{~mm}$. On the left side it varied between 32.1 to $41.4 \mathrm{~mm}$ (Table1).

\begin{tabular}{|l|l|}
\hline & Mean distance from incisive foramen \\
\hline Right foramen & $36.59 \pm 2.87 \mathrm{~mm}$ \\
\hline Left foramen & $36.737 \pm 2.90 \mathrm{~mm}$ \\
\hline
\end{tabular}

Table (1): Mean distance of greater palatine foramen from incisive foramen.

C) Size: On the right side: AP. Diameter varied between $2.3-6.42 \mathrm{~mm}$. Transverse diameter varied from1.76-5.27 $\mathrm{mm}$.

On the left side: AP. Diameter varied from 2.11-7.26mm. Transverse diameter varied from 1.85- 4.29(table 2) and (Figure 3).

\begin{tabular}{|l|ll|ll|}
\hline & \multicolumn{2}{|l|}{ AP. diameter } & \multicolumn{2}{|l|}{ Transverse. diameter } \\
\hline Right side & 4.45 & $\pm 1.01 \mathrm{~mm}$ & $3.35 \pm$ & $0.79 \mathrm{~mm}$ \\
\hline Left side & 4.50 & $\pm 1.12 \mathrm{~mm}$ & $3.26 \pm$ & $0.61 \mathrm{~mm}$ \\
\hline
\end{tabular}

Table(2):Mean AP and T diameter of greater palatine foramen in 100 adult skulls.

There was no significant change from right to left side $\mathrm{p}=0.38(\mathrm{p} \geq 0.05)$.

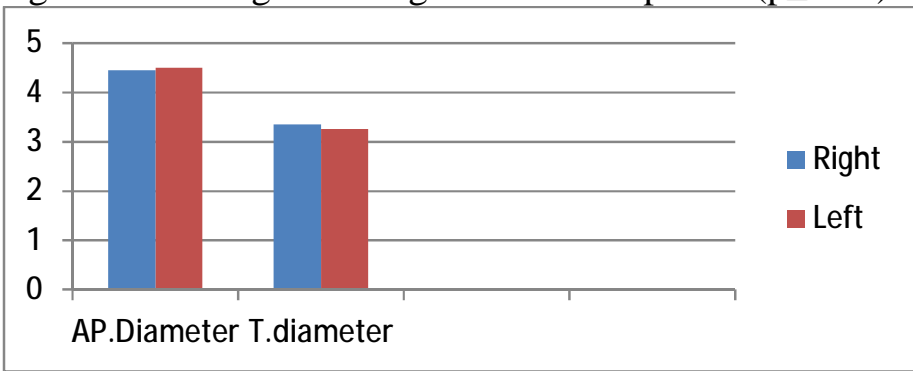

Figure (3): Mean AP and T diameter of greater palatine foramen in 100 adult skulls. 


\section{Discussion:}

Greater palatine canal approach to maxillary nerve block, demands aperfect three-dimensional orientation of its position. The preliminary stepis identification of GPF. Utilizing multiple anatomical landmarks toidentify the GPF increases the accuracy and minimizes the complicationsof injecting anaesthetic drug(Viveka and Kumar, 2016).

The present study provides valuable new data pertaining to the greaterpalatine foramen in relation to the surrounding anatomical landmarks inupper Egypt Population specific linear measurements have a clinicalimplication as it will enable clinicians to locate the greater palatineforamen in a consistently reliable manner thus avoiding injury to theneurovascular bundle that exit through it.

The modal position of the greater palatine foramen in the presnt studywas $\quad 47 \% \quad$ opposite $3^{\text {rd }}$ molar. $27 \%$ opposite $\quad 2^{\text {nd }}$ molar. $26 \%$ between $\quad 2^{\text {nd }}$ and 3 rd molars.Ilayperuma et al.,2014 on study on 136 dry skulls foundthat in Sri Lankans it was in line with the long axis of the third uppermolar $(55.56 \%)$. While it was in majority of the skulls (77.14\%) in studyof Chopra et al.,2016who studied on 100 dry skulls.Also in study ofSaralaya and Nayak,2007 (74.6\%), but different from Chinese where itwas found predominantly between the second and third molars (Wang etal., 1988).

The results of the current study further highlight the racial differences inthe modal position of the greater palatine foramen in relation to the uppermolars observed among different populations. Such diversity in thelocation of greater palatine foramen may be attributed to ethnic factors(Cutright et al., 2003).
The anatomy of the GPF is bound to gain even more attention, as throughthe GPF it is possible to stimulate the pterygopalatine ganglion (Piagkouet al., 2012). This can be used in stroke patients to reduce the stroke'seffect, but also to intervene in patients with cluster and migraineheadaches, as well as cerebral vasospasm conditions (Oluigbo et al.,2011).

In the present study,the distance from the GPF to the incisive fosse was $36.59 \mathrm{~mm}$ on right and $36.73 \mathrm{~mm}$ on left. The distance from the GPF tothe incisive fosse was $37.3 \mathrm{~mm}$ on the left side and $37.2 \mathrm{~mm}$ on the rightside in the study of Saralaya and Nayak, 2007 which was close to thoseof the present study. The mean distance on the right side was 36.21 $\pm 3.16 \mathrm{~mm}$ (and $36.52 \pm 3.34 \mathrm{~mm}$ on the left side in the study ofChrcanovicand Custódio,2010. While by Viveka and Kumar, 2016 it was $39.67 \mathrm{~mm}$ right and $37 \mathrm{~mm}$ on left.

Conclusion: Since a significant difference in the different parameters were found in studies when compared with other authors from different region of world, this clearly indicates that anthropologically, the positions of the GPF differ among ethnic groups. The present data will be helpful in comparing the skulls with those from various other regions as well as skulls of different races. The data of the present study will also be helpful for clinicians anaesthetists and as well as for maxillofacial surgeons.

\section{References:}

1- Ashwini, H. and Jaishree (2014): The Morphometric Study of PalatineForamen in Dry Adult Skulls. Indian Journal of Medical Case Reports, 3(4): 73-77. 
2- Baddour, H. M., Hubbard, A. M., and Tilson, H. B. (1979): Maxillary nerve block used prior to awake nasal intubation. Anesth.Prog, 26(2):43-5.

3- Bell, G. (2011): Oro-antral fistulae and fractured tuberosities. Br Dent J., 211:119-123.

4- Chopra, V., Singh, A.P., Chopra, R. and Joshi, H. (2016): Location of greater palatine foramen in the Indian population. SMU Medical Journal, 3(2):205-214.

5- Chrcanovic, B. R., and Custódio, A. L. (2010): Anatomical variation inthe position of the greater palatine foramen. J. Oral Sci., 52(1):109-13.

6- Cutright, B., Quillopa, N. and Schubert, W. (2003): An anthropometric analysis of the key foramina for maxillofacial surgery. J Oral Maxillofac Surg., 61(3):354357.

7- Ilayperuma, I., Nanayakkara, G. and Palahepitiya, N. (2014):Morphometric Evaluation of the Greater Palatine Foramen in Adult SriLankan Skulls. Int. J. Morphol., 32(4):1418-1422.

8- Ilayperuma, I., Nanayakkara, G. and Palahepitiya, N. (2009): Morphometric analysis of the mental foramen in adult Sri Lankan mandibles. Int. J. Morphol., 27(4):1019-24.

9- Jaffar, A. A. and Hamadah, H. J. (2003): An analysis of the position ofpalatine foramen. J. Basic Med. Sci., 3(1):24-32.

10- Klosek, S.K. and Rungruang, T. (2009): Anatomical study of the greater palatine artery and related structures of the palatal vault: considerations for palate as the

subepithelial connective tissue graft donor site. SurgRadiol

Anat.,31:245-250.

11- Kumar, A., Ritu and Akhtar, J., (2015): Variations in jugular foramen of human skull. Asian $\mathrm{J}$ of Med Sci, 6 (2): 95-98.

12- Lepere, A. J. (1993): Maxillary nerve block via the greater palatine canal: new look at an old technique. Anesth. Pain Control Dent., 2 (4): $195-7$.

13- Methathrathip, D., Apinhasmit, W., Chompoopong, S., Lertsirithong,A.,Ariyawatkul,T. andSangvichien, S. (2005): Anatomy of greaterpalatine foramen and canal and pterygopalatine fossa in Thais:considerations for maxillary nerve block. Surg. Radiol. Anat., 27(6):511-6.

14- Oluigbo, C.O., Makonnen, G. and Narouze, S. (2011):Sphenopalatine ganglion interventions: technical aspects and application. ProgNeurol Surg., 24:171-179.

15-Piagkou, M., Xanthos, T., Anagnostopoulou, S., Demesticha T . , Kotsiomitis, E., Piagkos, G., Protogerou, V., Lappas, D., Skandalakis, P. andJohnson, E.O.(2012):Anatomical variation and morphology in the position of the palatine foramina in adult human skulls from Greece. J Cranio maxilla fac Surg.,40: 206-210.

\begin{tabular}{|c|c|c|}
\hline $\begin{array}{c}\text { 16-Sangari,S.K., } \\
\text { Heineman,T. } \\
\text { E.P.(2015):Din }\end{array}$ & $\begin{array}{c}\text { Dossous, } \\
\text { and } \\
\text { nensions }\end{array}$ & $\begin{array}{l}\text { P.M. } \\
\text { Mtui, } \\
\text { and }\end{array}$ \\
\hline Anatomical & Variants & $f$ the \\
\hline Foramen Trans & versariun & \\
\hline Cervical & Vertebrae. & natomy \\
\hline
\end{tabular}


17- Saralaya, V. and Nayak, S. R. (2007): The relative position of thegreater palatine foramen in dry Indian skulls. Singapore Med. J.,48(12):1143-6.

18- Sethi, M., Vasudeva, N. and Mishra, S.(2014): Study of foramen transversaria of first cervical vertebrae and its variations. OA Anatomy, 17;2(3):25.

19- Sharma,N. A. and Garud, R.S.(2013): Greater palatine foramen - keyto successful hemimaxillaryanaesthesia: a morphometric study and reportof a rare aberration. Singapore Med J.,54 (3): 152-159.

20- Teixeira, C.S., Souza, V.R., Marques, C.P., Junior, S.W. and Pereira,K.F.(2010): Topography of the greater palatine foramen in maceratedskulls J. Morphol. Sci., 27(2): 88-92.

21- , S. and Kumar, M. (2016): Radiological Localization of GreaterPalatine Foramen Using Multiple Anatomical Landmarks MOJ Anat andPhysiol, 2(7): 72.

22- Wang, T.M., Kuo, K.J.,Shih, C., Holl and Liv, J.C. (1988):Assesment of the relative locations of the Greater palatine foramen in adult Chinese skulls.ActaAnat (Basel),132: 182186.

23- Williams, P. L., Bannister, L. H., Berry, M. M., Collins, P., Dyson, M.and Dussek, J. E.(2000):Gray's Anatomy: The anatomical basis ofmedicine and surgery. 38th ed. New York, Churchill Livingstone. 